\title{
Liver necrosis and lipid peroxidation in the rat
}

\author{
By J. BUNYAN, J. GREEN AND A. T. DIPLOCK \\ Walton Oaks Experimental Station, Vitamins Ltd, Dorking Road, Tadworth, Surrey
}

(Received 4 June 1962-Revised I I Fuly 1962)

Vitamin $\mathbf{E}$ or selenium prevents the development of dietary necrotic liver degeneration in rats (Schwarz \& Foltz, 1957), and each also protects chicks against exudative diathesis (Schwarz, Bieri, Briggs \& Scott, 1957). Vitamin E has been said to function as an intracellular antioxidant, protecting against the harmful effects of lipid peroxidation. In accord with this theory and with the fact that the action of Se, in many respects, parallels that of vitamin E, some authors have claimed that Se forms antioxygenic compounds in vivo (e.g. Bieri, Dam, Prange \& Søndergaard, 1961). However, Bunyan, Diplock, Edwin \& Green (I962) have shown that the action of vitamin $\mathrm{E}$ and $\mathrm{Se}$ in preventing exudative diathesis in chicks differs from that of a conventional antioxidant and have suggested that any activity they have as antioxidants in vivo is not an essential part of their primary function. Consequently it seemed important to discover also to what extent a decrease in lipid peroxidation is involved in preventing liver necrosis in rats. To do so, we have investigated the effects of various dietary levels of Se, vitamin E and DPPD $\left(N, N^{\prime}\right.$-diphenyl-p-phenylenediamine) on the incidence of liver necrosis and on lipid peroxidation in the tissues. Preliminary results have been described by Edwin, Bunyan, Diplock \& Green (I96r).

\section{EXPERIMENTAL}

Rats. Norwegian hooded rats about 4 weeks old were allocated at random to the experimental groups described below, with equal numbers of each sex and litter-mate control, when possible. Previously, the rats had received the vitamin E-deficient diet E IoY (Diplock, Edwin, Bunyan \& Green, I96r).

Diets. The necrogenic diet had the percentage composition: dried baker's yeast (United Yeast Co. Ltd, Croydon, Surrey) 30, sucrose 45, glucose $14 \cdot 6$, lard 5 , salt mixture 5 and vitamin mixture 0.4 , and was supplemented with vitarnin A, 8 i.u./g, vitamin $D_{3}, 2$ i.u./g and menaphthone, $0.1 \mu \mathrm{g} / \mathrm{g}$. The baker's yeast was heated at $100^{\circ}$ for $2 \mathrm{~h}$ and ground before use. The vitamin mixture supplied ( $\mathrm{mg} / \mathrm{kg}$ ): thiamine 9 , riboflavin 19, nicotinic acid 90, pyridoxine 9, calcium pantothenate 90, folic acid 2, cyanocobalamin 0.3 , inositol $90, p$-aminobenzoic acid 90 and choline dihydrogen tartrate 900. The salt mixture supplied $(\mathrm{g} / \mathrm{kg}): \mathrm{CaH}_{4}\left(\mathrm{PO}_{4}\right)_{2} \cdot 2 \mathrm{H}_{2} \mathrm{O} 2 \mathrm{I}_{7}{ }_{7}, \mathrm{NaH}_{2} \mathrm{PO}_{4}$. ${ }_{2} \mathrm{H}_{2} \mathrm{O} 5 \cdot 7, \mathrm{KCl}_{13} \cdot 5, \mathrm{NaCl} 2 \cdot 7, \mathrm{MgSO}_{4} \cdot 7 \mathrm{H}_{2} \mathrm{O}_{4} \cdot 4$, ferric citrate 1.9, $\mathrm{KI} 0.055$, $\mathrm{NaF} 0.014, \mathrm{MnSO}_{4} .4 \mathrm{H}_{2} \mathrm{O} 0.070, \mathrm{Cu}_{2} \mathrm{I}_{2} 0.005, \mathrm{Al}_{2}\left(\mathrm{SO}_{4}\right)_{3} \mathrm{~K}_{2} \mathrm{SO}_{4} .24 \mathrm{H}_{2} \mathrm{O} 0.005$.

Incidence of liver necrosis. Liver necrosis was detected by macroscopic changes seen on death or after slaughter. Rats that died during the test and were partly eaten by 
the survivors were also counted as succumbing to liver necrosis, although their livers could not be examined.

Determination of lipid peroxidation in tissues. A sample of liver or kidney was made into a $20 \mathrm{mg} / \mathrm{ml}$ homogenate in ice-cold phosphate buffer $(0.09 \mathrm{M}, \mathrm{pH} 7.4)$ by means of a nylon-glass homogenizer. Peroxidation was studied in vitro by shaking $5 \mathrm{ml}$ of the homogenate at 100 excursions $/ \mathrm{min}$ for $60 \mathrm{~min}$ in a water-bath at $37^{\circ}$. After addition of $35 \%$ (w/v) trichloroacetic acid solution $(5 \mathrm{ml})$, cooling and filtration, a portion of the filtrate was added to an equal volume of $0.5 \%(\mathrm{w} / \mathrm{v})$ thiobarbituric acid solution in water, and the mixture was heated in boiling water for $10 \mathrm{~min}$. After the solution had cooled in ice-water for $3 \mathrm{~min}$, the optical density of the pink colour was read in a Unicam S.P. 600 spectrophotometer at $53^{\circ} \mathrm{m} \mu$ or in an EEL (Evans Electroselenium Ltd) long-cell absorptiometer with an Ilford Filter $604\left(\lambda_{\max } 520 \mathrm{~m} \mu\right)$. Both instruments were calibrated with crystalline malonaldehyde bisbisulphite disodium salt, prepared by the method of Saslaw \& Waravdekar (1957). Results are reported as $\mu \mathrm{g}$ malonaldehyde/g tissue. Peroxidation at zero time was measured by adding trichloroacetic acid solution to the homogenate as soon as it was prepared and proceeding as described above.

Expt $\mathrm{r}$. Twenty-nine male rats were allocated at random to three groups, to receive severally, necrogenic diet, necrogenic diet $+\mathrm{Se}, 0.05$ p.p.m. and necrogenic diet $+\mathrm{Se}$, 0.50 p.p.m. Se was added to the diet as sodium selenite. Tissues of five rats from each group were studied 20-23 days later, and all survivors were killed and examined for liver necrosis at $3^{8}$ days.

Table 1. Expt I. Effects of dietary sodium selenite on liver necrosis and lipid peroxidation in rats

\begin{tabular}{|c|c|c|c|c|}
\hline \multirow{2}{*}{$\begin{array}{l}\text { Addition to } \\
\text { necrogenic diet }\end{array}$} & \multirow{2}{*}{$\begin{array}{l}\text { Incidence of } \\
\text { liver necrosis } \\
\text { among rats } \\
\text { killed for } \\
\text { tissue analysis } \\
\text { (20-23 days) }\end{array}$} & \multirow{2}{*}{$\begin{array}{l}\text { Death rate } \\
\text { of remainder } \\
\text { to } 38 \text { days }\end{array}$} & \multicolumn{2}{|c|}{$\begin{array}{l}\text { Malonaldehyde ( } \mu \mathrm{g} / \mathrm{g} \text { tissue) } \\
\text { (mean with standard deviation } \\
\text { After } 60 \mathrm{~min} \text { at } 37^{\circ}\end{array}$} \\
\hline & & & Liver & Kidney \\
\hline None & $I / 5$ & $3 / 4$ & $27 \pm 4.7$ & $18 \pm 2.0$ \\
\hline $\begin{aligned} \text { Se: } & 0.05 \text { p.p.m. } \\
& 0.50 \text { p.p.m. }\end{aligned}$ & $\begin{array}{l}0 / 5 \\
0 / 5\end{array}$ & $\begin{array}{l}0 / 5 \\
0 / 5\end{array}$ & $\begin{array}{l}25 \pm 2 \cdot 9 \\
21 \pm 5 \cdot 7\end{array}$ & $\begin{array}{r}19 \pm 3.3 \\
13 * 3.8\end{array}$ \\
\hline
\end{tabular}

Expt 2. In this experiment we used two groups of seven or eight rats, of both sexes, on each diet, with litter-mate control whenever possible. One group of rats was killed for tissue analysis at 23-29 days. Livers and kidneys of these rats were examined individually. Rats of the other group were used to determine the incidence of liver necrosis. The diets consisted of the necrogenic diet or this diet with supplements of vitamin E (D- $\alpha$-tocopheryl acetate), 10 or 20 p.p.m., DPPD, 20 or 40 p.p.m. and $\mathrm{Se}, 0.05$ p.p.m. The test was concluded at 56 days, survivors being killed for examination.

Expt 3. Sixteen male rats were divided at random into two groups of eight. Both groups received the necrogenic diet, but one group was also given orally $2 \mathrm{mg}$ toco- 
pheronolactone/rat daily as a solution in ethyl oleate. All survivors were killed at 56 days. Lipid peroxidation in the tissues was not studied. Tocopheronolactone is the name proposed by Green, Edwin, Diplock \& Bunyan ( 1961 ) for the lactone of the water-soluble metabolite of $\alpha$-tocopherol isolated by Simon, Eisengart, Sundheim \& Milhorat (1956).

\section{RESULTS}

Expt $\mathrm{I}$. The results are shown in Table $\mathrm{I}$. Tests for peroxides extended over the period from 20 to 23 days which, judged by the incidence of liver necrosis or death in controls, or both, coincides with the latent period of the disease (Chernick, Moe, Rodnan \& Schwarz, 1955). Although 0.05 p.p.m. Se clearly protected against liver necrosis, livers and kidneys of rats receiving this amount of Se developed about the same amount of malonaldehyde as deficient rat tissues, whether tested before or after incubation at $37^{\circ}$. Se at $0.5 \circ$ p.p.m. resulted in significantly less malonaldehyde formation in kidney but not in liver.

Expt 2. The results are shown in Table 2. Vitamin E, at both dietary concentrations, prevented the onset of liver necrosis up to 56 days after the beginning of the test, but had no significant effects on tissue peroxidation. DPPD, at 20 p.p.m., allowed five rats out of eight to develop liver necrosis. Mean peroxidation in liver appeared lower, but the difference was not statistically significant $(0.1>P>0.05)$. However at 40 p.p.m. peroxidation was significantly reduced in both liver and kidney $(P<0.001)$, but liver necrosis was not prevented, as three rats out of seven in this group died. Dietary addition of 0.05 p.p.m. Se was again completely protective against liver necrosis, but it did not affect tissue peroxides.

Expt 3. The results of giving tocopheronolactone by mouth are shown in Table 2. This substance was completely ineffective against liver necrosis.

\section{DISCUSSION}

In these experiments, we measured lipid peroxidation by using the thiobarbituric acid reagent to determine malonaldehyde, which is assumed to be a product of the oxidative breakdown of unsaturated fatty acids (Wilbur, Bernheim \& Shapiro, 1949; Caputto, McCay \& Carpenter, I961), although malonaldehyde may also be formed by the oxidation of other compounds (Kohn \& Liversedge, 1944; Waravdekar \& Saslaw, 1959). Homogenates of necrotic livers showed increased amounts of malonaldehyde after incubation, but there were no differences from the normal in vivo (at zero time). Schwarz (196I) was also unable to find increased amounts even in the advanced phases of liver necrosis, provided that the organs were tested immediately after removal. These findings show either that the amount of lipid peroxides is not raised in vivo in liver necrosis, or that if so raised the peroxides do not break down to give malonaldehyde during the rapid handling of ice-cold tissue. The first alternative is difficult to establish, by the test for malonaldehyde, because this compound may be metabolized rapidly in vivo; Caputto et al. (I96I) could recover only half of a dose of malonaldehyde $10 \mathrm{~min}$ after injection. It is also difficult to prove that the 


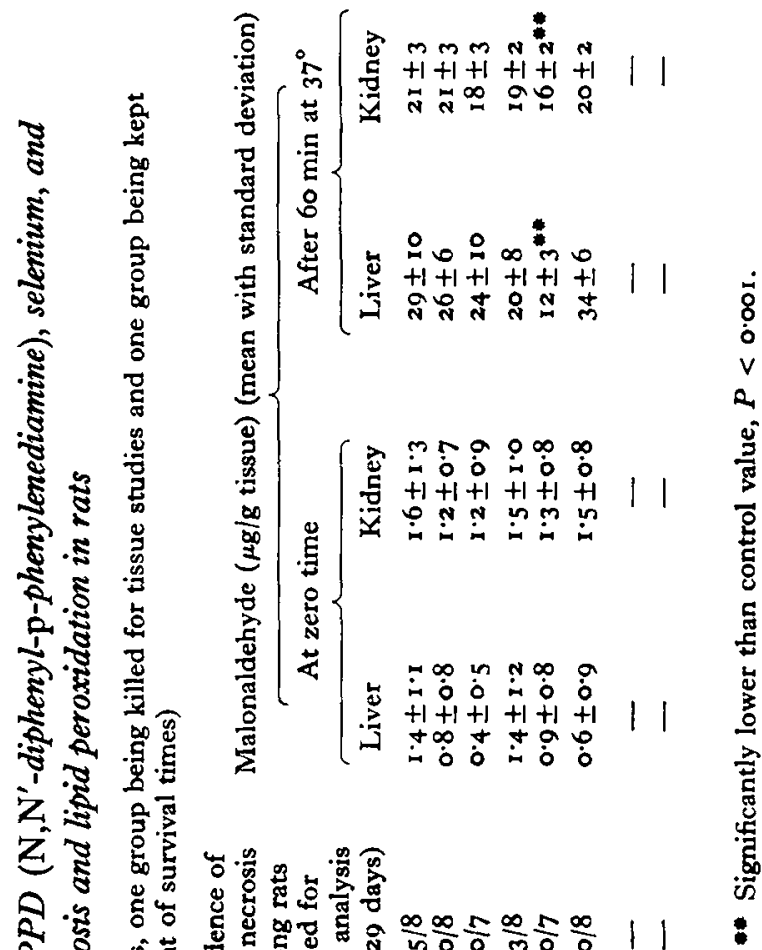

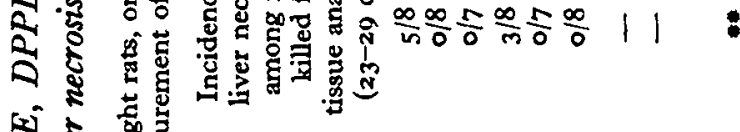

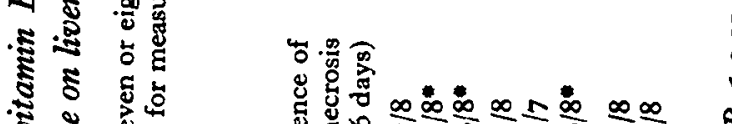

:

bे

ఫัँ

要

ar

m हूँ

है

N

密

a

(i)

营

$\stackrel{\text { E }}{E}$

落 N 
malonaldehyde formed in vitro is derived solely from peroxides that already existed in vivo, since it is clearly possible for more peroxides to form and decompose during the aerobic incubation.

Many workers have lately used the thiobarbituric acid reagent for investigating the biological functions of vitamin E and Se (Tappel \& Zalkin, 1959; Zalkin, Tappel \& Jordan, 1960; Bieri \& Anderson, 1960; Bieri et al. 196r). Results of these experiments, mostly from studies in vitro, have usually been interpreted as showing antioxidant function in vivo for both vitamin $E$ and Se. Such experiments were criticized by Bunyan et al. (1962) in two ways. First, not all tissues gave results supporting the antioxidant hypothesis and, secondly, dietary concentrations of vitamin $\mathrm{E}$ were usually above the minimum required to prevent signs of deficiency, other than excessive malonaldehyde formation, in vitro. Bunyan et al. (1962) showed how tests at minimal dietary concentrations could reveal differences between the action of vitamin $\mathrm{E}$ or Se and that of conventional antioxidants, even though based only upon tests in vitro. Consequently, in spite of doubts about the interpretation of malonaldehyde formation in vitro, we carried out similar experiments on liver necrosis in the rat.

The results of these tests show that small amounts of Se sufficient to prevent liver necrosis ( 0.05 p.p.m.) do not decrease peroxidation in rat liver and kidney in vitro. However, at ten times this dietary concentration, sodium selenite significantly lowered peroxidation in kidney by about one-third but had a lower, and non-significant, effect in liver. Though this effect in kidney supports the idea that Se forms antioxygenic compounds in vivo, the lack of effect at the lower dietary concentration suggests that a decrease in peroxidation in vitro is not of primary significance in relation to the dramatic protection that Se affords against liver degeneration. Corwin (1962) distinguished 'endogenous peroxide formation' in rat liver homogenates from 'enzymic peroxide formation', in the presence of added substrates, and suggested that the former depends upon damage to subcellular structures in the medium used for homogenization, being greater for buffered $0.18 \mathrm{M}$-saline $(\mathrm{pH} 7 \cdot 4)$ than for $0.25 \mathrm{M}$ sucrose. He found that dietary $\mathrm{Se}(0.07$ p.p.m.) seemed somewhat to inhibit endogenous peroxide formation in the buffered saline, although not significantly, but that Se caused enzymic peroxide formation to increase. In our tests, dietary Se (0.05 p.p.m.) did not decrease endogenous peroxide formation, but less malonaldehyde $(27 \mu \mathrm{g} / \mathrm{g})$ was formed in our $0.09 \mathrm{M}$-phosphate buffer after $\mathrm{I} h$ than was found by Corwin after $\mathrm{I}_{2}^{\mathrm{l}} \mathrm{h}$. It might be of interest to compare the effects of dietary Se on both types of peroxidation in the various media discussed.

If, as our results show, dietary Se prevents necrosis by a mechanism that does not involve a decrease in lipid peroxidation, it is possible that vitamin $\mathrm{E}$ may do the same. Direct proof is difficult because some degree of inhibition of malonaldehyde formation is unavoidable with vitamin $E$ in the tissue. However, our results support the hypothesis by showing that a dietary concentration of vitamin $E$ (ro p.p.m.) inhibiting lipid peroxidation by only 10\% completely prevents liver necrosis. The primary effect of vitamin $\mathrm{E}$, as of Se, may therefore be on some other biochemical or biophysical system concerned in the maintenance of cell integrity. 
Disparity between the extent of liver necrosis and peroxidation in vitro is again found in the results with DPPD. In contrast to vitamin $E$ with its selective action on liver necrosis, DPPD, at 40 p.p.m. in the diet, significantly inhibited peroxidation in liver and kidney, but did not completely prevent the onset of the disease. The other results for these two substances also show that DPPD has a greater effect on peroxides than on liver necrosis. Schwarz (1958) found that higher concentrations of DPPD prevented liver necrosis completely, and it therefore seems that both vitamin $\mathrm{E}$ and DPPD are effective against the disease and against malonaldehyde formation in vitro, but that DPPD replaces vitamin $E$ less effectively in the first action than in the second. There may be no causal connexion between the two phenomena, since, as we found with Se, undiminished peroxidation in vitro can occur in the total absence of liver necrosis.

Daily doses of $2 \mathrm{mg}$ tocopheronolactone failed to prevent liver degeneration, although this substance restores respiration in homogenates of prenecrotic rat liver (Corwin \& Schwarz, 1960). A possible explanation is that tocopheronolactone given by mouth is not stored in the tissues.

\section{SUMMARY}

I. Liver necrosis in rats has been studied, with special reference to lipid peroxidation occurring in liver and kidney.

2. Peroxidation was measured by means of thiobarbituric acid, and the limitations of this method are discussed. Selenium had no effect on peroxidation when given at 0.05 p.p.m. in the diet, although it completely prevented liver necrosis. At 0.5 p.p.m. Se significantly decreased peroxidation in the kidney.

3. D- $\alpha$-tocopheryl acetate at to or 20 p.p.m. in the diet decreased the incidence of liver necrosis markedly, but the effects on peroxidation in liver and kidney were small and not significant.

4. DPPD ( $N, N^{\prime}$-diphenyl-p-phenylenediamine) was tested at 20 and 40 p.p.m. in the diet. At 40 p.p.m. it significantly decreased peroxidation in liver and kidney, but did not completely prevent liver necrosis. DPPD had more effect on peroxidation and less on liver necrosis than similar levels of vitamin $\mathrm{E}$.

5. Tocopheronolactone, given daily by mouth, was ineffective in preventing liver necrosis.

6. The hypothesis of a simple in vivo antioxidant role for vitamin $\mathrm{E}$ and $\mathrm{Se}$ is discussed and criticized.

We thank Miss R. J. Castle for skilled assistance.

\section{REFERENCES}

Bieri, J. G. \& Anderson, A. A. (1960). Arch. Biochem. Biophys. 90, 105.

Bieri, J. G., Dam, H., Prange, I. \& Sondergaard, E. (196r). Acta physiol. scand. 52, 36.

Bunyan, J., Diplock, A. T., Edwin, E. E. \& Green, J. (1962). Brit. F. Nutr. 16, 519.

Caputto, R., McCay, P. B. \& Carpenter, M. P. (I96I). Amer. F. clin. Nutr. 9, part 4, no. 2, p. 6r.

Chernick, S. S., Moe, J. G., Rodnan, G. P. \& Schwarz, K. (1955). F. biol. Chem. $217,829$.

Corwin, L. M. (1962). Arch. Biochem. Biophys. 97, 51.

Corwin, L. M. \& Schwarz, K. (1960). F. biol. Chem. 235, 3387. 
Diplock, A. T., Edwin, E. E., Bunyan, J. \& Green, J. (196r). Brit. Y. Nutr. 15, 425.

Edwin, E. E., Bunyan, J., Diplock, A. T. \& Green, J. (1961). Nature, Lond., 189, 747.

Green, J., Edwin, E. E., Diplock, A. T. \& Bunyan, J. (I961). Biochim. biophys. Acta, 49, 417.

Kohn, H. I. \& Liversedge, M. (1944). Y. Pharmacol. 82, 292.

Saslaw, L. D. \& Waravdekar, V. S. (1957). F. org. Chem. 22, 843.

Schwarz, K. (1958). Proc. Soc. exp. Biol., N.Y., 99, 20.

Schwarz, K. (1961). Amer. Y. clin. Nutr. 9, part 4, no. 2, p. 94.

Schwarz, K., Bieri, J. G., Briggs, G. M. \& Scott, M. L. (1957). Proc. Soc. exp. Biol., N. Y., $95,621$.

Schwarz, K. \& Foltz, C. M. (1957). F. Amer. chem. Soc. 79, 3292.

Simon, E. J., Eisengart, A., Sundheim, L. \& Milhorat, A. T. (1956). Э. biol. Chem. $221,807$.

Tappel, A. L. \& Zalkin, H. (1959). Arch. Biochem. Biophys. 80, 333.

Waravdekar, V. S. \& Saslaw, L. D. (1959). F. biol. Chem. 234, I 945.

Wilbur, K. M., Bernheim, F. \& Shapiro, O. W. (1949). Arch. Biochem. Biophys. 24, 305.

Zalkin, H., Tappel, A. L. \& Jordan, J. P. (rg60). Arch. Biochem. Biophys. 91, 117. 